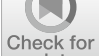

updates

Cite as

Nano-Micro Lett.

(2020) 12:104

Received: 12 February 2020

Accepted: 28 March 2020

Published online: 2 May 2020

(C) The Author(s) 2020

\section{A Superaerophobic Bimetallic Selenides Heterostructure for Efficient Industrial-Level Oxygen Evolution at Ultra-High Current Densities}

\author{
Jiaxin Yuan ${ }^{1}$, Xiaodi Cheng ${ }^{1}$, Hanqing Wang ${ }^{1}$, Chaojun Lei ${ }^{1}$, Sameer Pardiwala ${ }^{1}$, \\ Bin Yang ${ }^{1}$, Zhongjian $\mathrm{Li}^{1}$, Qinghua Zhang ${ }^{4}$, Lecheng Lei ${ }^{1}$, Shaobin Wang ${ }^{5}$, \\ Yang Hou ${ }^{1,2,3} \otimes$ \\ $\bowtie$ Shaobin Wang, shaobin.wang@adelaide.edu.au; Yang Hou, yhou@zju.edu.cn \\ 1 Key Laboratory of Biomass Chemical Engineering of Ministry of Education, College of Chemical \\ and Biological Engineering, Zhejiang University, Hangzhou 310027, People's Republic of China \\ 2 Institute of Zhejiang University - Quzhou, Quzhou 324000, People's Republic of China \\ 3 Ningbo Research Institute, Zhejiang University, Ningbo 315100, People's Republic of China \\ 4 Zhejiang Provincial Key Laboratory of Advanced Chemical Engineering Manufacture Technology, \\ College of Chemical and Biological Engineering, Zhejiang University, Hangzhou 310027, \\ People's Republic of China \\ 5 School of Chemical Engineering and Advanced Materials, The University of Adelaide, Adelaide, SA 5005, \\ Australia
}

\title{
HIGHLIGHTS
}

- A superaerophobic heterostructured nanowrinkles of bimetallic selenides is developed.

- The 3D heterostructure exhibits excellent activity and stability towards oxygen evolution reaction (OER) in base.

\begin{abstract}
Cost-effective and stable electrocatalysts with ultra-high current densities for electrochemical oxygen evolution reaction (OER) are critical to the energy crisis and environmental pollution. Herein, we report a superaerophobic three dimensional (3D) heterostructured nanowrinkles of bimetallic selenides consisting of crystalline $\mathrm{NiSe}_{2}$ and $\mathrm{NiFe}_{2} \mathrm{Se}_{4}$ grown on $\mathrm{NiFe}$ alloy $\left(\mathrm{NiSe}_{2} / \mathrm{NiFe}_{2} \mathrm{Se}_{4} @ \mathrm{NiFe}\right)$ prepared by a thermal selenization procedure. In this unique $3 \mathrm{D}$ heterostructure, numerous nanowrinkles of $\mathrm{NiSe}_{2} / \mathrm{NiFe}_{2} \mathrm{Se}_{4}$ hybrid with a thickness of $\sim 100 \mathrm{~nm}$ are grown on $\mathrm{NiFe}$ alloy in a uniform manner. Profiting by the large active surface area and high electronic conductivity, the superaerophobic $\mathrm{NiSe}_{2} / \mathrm{NiFe}_{2} \mathrm{Se}_{4} @ \mathrm{NiFe}$ heterostructure exhibits excellent electrocatalytic activity and durability towards OER in alkaline media, outputting the low potentials of 1.53 and $1.54 \mathrm{~V}$ to achieve ultra-high current densities of 500 and $1000 \mathrm{~mA} \mathrm{~cm}^{-2}$, respectively, which is among the most active Ni/Fe-based selenides, and even superior to the benchmark $\mathrm{Ir} / \mathrm{C}$ catalyst. The in-situ derived $\mathrm{FeOOH}$ and

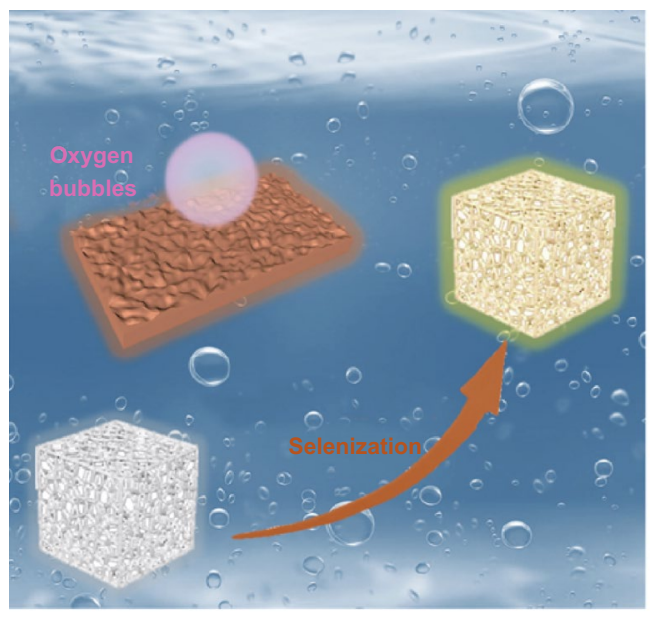
$\mathrm{NiOOH}$ species from $\mathrm{NiSe}_{2} / \mathrm{NiFe}_{2} \mathrm{Se}_{4} @ \mathrm{NiFe}$ are deemed to be efficient active sites for OER.

KEYWORDS Superaerophobicity; Bimetallic selenide; Heterostructure electrocatalyst; Strong interfacial coupling; Oxygen evolution reaction
\end{abstract}




\section{Introduction}

With the ever-worsening energy and environmental crises, electrocatalytic water-splitting is believed as a promising method to resolve the global tremendous energy needs of future societies $[1,2]$. However, the sluggish reaction kinetics of four-protoncoupled electron transfer processes of oxygen evolution reaction (OER) is the bottleneck in the water-splitting process [3, 4]. Normally, the best known electrocatalysts are Ir/Ru-based materials for OER catalysis [5]. However, high cost and limited reserves largely prevent their large scale applications. Hence, development of low-cost and highly efficient non-noble metal OER electrocatalysts has been an active research in recent years, such as transition metal ( $\mathrm{Ni}, \mathrm{Fe}$, or $\mathrm{Co}$, etc.) phosphides [6-9], sulfides [10-16], selenides [17-20], carbides [21, 22], nitrides [23-25], hydroxides [26], oxides [27], and chalcogenides [28]. Among these reported transition metal compounds, transition metal-based selenides are specifically attractive for OER, due to their metallic nature with high intrinsic electronic conductivity. Compared with single metal-based counterparts, bimetallic selenides have been the recent focus in OER electrocatalysts, thanks to their synergistic electronic effects [29, 30].

Besides, the synergistically united advantages of each component to boost water-splitting activity, the synergistic effect of heterostructure of bimetallic selenides can efficiently improve the structural stability and promote the generation of active phases during the OER process [31]. However, bimetallic selenides as efficient OER electrocatalysts are still in infancy, and the specific mechanism of the synergistic effect between heterogeneous structures has not been clearly understood [32]. In addition, their catalytic performances have not yet meet industrial demands for electrochemical water-splitting (high current density $>500 \mathrm{~mA} \mathrm{~cm}^{-2}$ ) [33, 34].

Herein, we developed a superaerophobic 3D heterostructure of bimetallic selenide consisting of crystalline $\mathrm{NiSe}_{2}$ and $\mathrm{NiFe}_{2} \mathrm{Se}_{4}$ nanowrinkles on backbones of 3D NiFe alloy, synthesized via a simple one-step thermal selenization procedure. The thickness of $\mathrm{NiSe}_{2} / \mathrm{NiFe}_{2} \mathrm{Se}_{4}$ nanowrinkles was about $100 \mathrm{~nm}$. On account of the high electronic conductivity and large active surface area, the $\mathrm{NiSe}_{2} / \mathrm{NiFe}_{2} \mathrm{Se}_{4} @$ $\mathrm{NiFe}$ heterostructure with high current densities of 500 and $1000 \mathrm{~mA} \mathrm{~cm}^{-2}$ could be output at low potentials of 1.53 and $1.54 \mathrm{~V}$, respectively, which are appreciably superior to almost all previously reported $\mathrm{Ni} / \mathrm{Fe}$-based selenides, and even better than commercial Ir/C catalyst. In-situ electrochemical Raman spectroscopy discovered that the formd $\mathrm{FeOOH}$ and $\mathrm{NiOOH}$ species are the real active phases in $\mathrm{NiSe}_{2} / \mathrm{NiFe}_{2} \mathrm{Se}_{4} @ \mathrm{NiFe}$ for OER catalysis. In addition, a special "superaerophobic" feature of $\mathrm{NiSe}_{2} / \mathrm{NiFe}_{2} \mathrm{Se}_{4} @ \mathrm{NiFe}$ enabled an outstanding capability to diminish the negative effects and promote rapid release of in-situ generated $\mathrm{O}_{2}$ bubbles during the OER process. Furthermore, the $\mathrm{NiSe}_{2} / \mathrm{NiFe}_{2} \mathrm{Se}_{4} @ \mathrm{NiFe}$ heterostructure as a bifunctional electrocatalyst exhibited superior electrocatalytic activity for overall-water-splitting in $10.0 \mathrm{M}$ $\mathrm{KOH}$ at $60^{\circ} \mathrm{C}$, driven at a low voltage of $2.17 \mathrm{~V}$ to achieve $1000 \mathrm{~mA} \mathrm{~cm}^{-2}$.

\section{Experimental Sections}

\subsection{Chemicals and Materials}

All reagents are analytical grade and used without further purifications. The NiFe alloy, Ni foam (NF), and Fe foam (IF) were purchased from Kunshan Longshengbao Electronic material store. The Se powder, $\mathrm{KOH}$, commercial $\mathrm{IrO}_{2}$, ethanol, and acetone were obtained from Alfa Aesar.

\subsubsection{Synthesis of $\mathrm{NiSe}_{2} / \mathrm{NiFe}_{2} \mathrm{Se}_{4} @ \mathrm{NiFe}$}

Commercial NiFe alloy was washed in an ultrasonic machine with acetone, hydrochloric acid, ethanol, and deionized water for $10 \mathrm{~min}$, respectively. After the above treatments, two pieces of NiFe alloy $\left(0.25 \times 1.5 \mathrm{~cm}^{2}\right)$ were thermally selenized at $300{ }^{\circ} \mathrm{C}$ for $2 \mathrm{~h}$ with $60 \mathrm{mg}$ of Se powder in a vacuum quartz tube. The mass loading of $\mathrm{NiSe}_{2} / \mathrm{NiFe}_{2} \mathrm{Se}_{4}$ on $\mathrm{NiFe}$ alloy was $\sim 5.0 \mathrm{mg} \mathrm{cm}^{-2}$.

\subsubsection{Synthesis of $\mathrm{Ni}_{0.7} \mathrm{Fe}_{0.3}-\mathrm{Se}$ and $\mathrm{Ni}_{0.5} \mathrm{Fe}_{0.5}-\mathrm{Se}$}

After the pre-treatments, the $\mathrm{Ni}_{0.7} \mathrm{Fe}_{0.3}$ alloy and $\mathrm{Ni}_{0.5} \mathrm{Fe}_{0.5}$ alloy were thermally selenized at $300{ }^{\circ} \mathrm{C}$ for $2 \mathrm{~h}$ with $60 \mathrm{mg}$ of Se powder in a vacuum quartz tube, respectively.

\subsubsection{Synthesis of NF-Se}

Commercial Ni foam was washed in an ultrasonic machine with acetone, hydrochloric acid, ethanol, and deionized water for $10 \mathrm{~min}$, respectively. After the above treatments, 
two pieces of Ni foam were thermally selenized at $300{ }^{\circ} \mathrm{C}$ for $2 \mathrm{~h}$ with $60 \mathrm{mg}$ of Se powder in a vacuum quartz tube. The mass loading of NF-Se on Ni foam was $\sim 4.7 \mathrm{mg} \mathrm{cm}^{-2}$.

\subsubsection{Synthesis of IF-Se}

Commercial Fe foam was washed in an ultrasonic machine with acetone, hydrochloric acid, ethanol, and deionized water for $10 \mathrm{~min}$, respectively. After the above treatments, two pieces of $\mathrm{Fe}$ foam were thermally selenized at $300{ }^{\circ} \mathrm{C}$ for $2 \mathrm{~h}$ with $60 \mathrm{mg}$ of Se powder in a vacuum quartz tube. The mass loading of IF-Se on Fe foam was $\sim 4.0 \mathrm{mg} \mathrm{cm}^{-2}$.

\subsection{Characterizations}

X-ray diffraction patterns (XRD) were examined on a RIGAKU D/MAX 2550/PC (RIGAKU D/MAX 2550/PC). Field-emission scanning electron microscopy (FESEM) images were investigated on a SU-8010 at an acceleration voltage of $5 \mathrm{kV}$. Transmission electron microscopy (TEM) images, high-resolution TEM (HRTEM) images, selectedarea electron diffraction (SAED) patterns were obtained on a JEM-2100 electron microscope (HRTEM, JEM-2100, $200 \mathrm{kV}$ ) equipped with an energy dispersive X-ray spectrometer, operating at $120 \mathrm{kV}$. Raman spectra were obtained by a Raman scattering spectroscopy system, excited with a $534 \mathrm{~nm}$ diode laser. The surface elemental information was obtained by X-ray photoelectron spectroscopy performed on the RIGAKU D/MAX 2550/PC (RIGAKU D/MAX 2550/ PC). Contact angles were analyzed via an OCA20 machine (Data-Physics, Germany) at room temperature. The atom ratio of $\mathrm{Fe}$ and $\mathrm{Ni}$ were analyzed via $\mathrm{X}$-ray fluorescence spectrometry (Rigaku, ZSX Primus II) at room temperature.

\subsection{Electrochemical Measurements}

All measured potentials in this work were reported versus reversible hydrogen electrode (RHE) according to the equation: $E_{\mathrm{RHE}}=E_{\text {applied }}+0.197+0.059 \mathrm{pH}$, where the $E_{\text {applied }}$ is the applied potential. Linear sweep voltammetry (LSV) curves were recorded at a voltage range of $1.2-0 \mathrm{~V}$ with a scan rate of $5 \mathrm{mV} \mathrm{s}^{-1}$. In OER performance test, all polarization curves were with iR compensation in this work unless otherwise noted. The long-term durability test was performed using a chronopotentionmetry method at a constant current density. The $C_{\mathrm{dl}}$ values of the as-prepared working electrodes were determined from the cyclic voltammogram (CV) in the double layer region (without Faradaic processes) at different scan rates.

\section{Results and Discussion}

\subsection{Structural Characterizations of $\mathrm{NiSe}_{2} / \mathrm{NiFe}_{2} \mathrm{Se}_{4} @$ $\mathrm{NiFe}$}

Figure 1a illustrates a facile thermal selenization process of 3D $\mathrm{NiSe}_{2} / \mathrm{NiFe}_{2} \mathrm{Se}_{4} @ \mathrm{NiFe}$ synthesis. The NiFe alloy was annealed at $300{ }^{\circ} \mathrm{C}$ for $2 \mathrm{~h}$ under a selenium vapor atmosphere to obtain the $\mathrm{NiSe}_{2} / \mathrm{NiFe}_{2} \mathrm{Se}_{4} @ \mathrm{NiFe}$. We systematically investigated the effects of different selenium contents and selenization temperatures on OER capacity, and the optimal amount of selenium powder was $60 \mathrm{mg}$ and annealing temperature was $300{ }^{\circ} \mathrm{C}$ (Figs. S1-S3). FESEM image reveal that the spatial skeleton morphology of the 3D $\mathrm{NiSe}_{2} /$ $\mathrm{NiFe}_{2} \mathrm{Se}_{4} @ \mathrm{NiFe}$ remained after the thermal selenization process (Fig. 1b, c) [35]. The $\mathrm{NiSe}_{2} / \mathrm{NiFe}_{2} \mathrm{Se}_{4} @ \mathrm{NiFe}$ heterostructure was consisted of numerous nanowrinkles with a thickness of $\sim 100 \mathrm{~nm}$. The corresponding energy-dispersive X-ray spectroscopy (EDX) element mapping images showed the uniform coverage of $\mathrm{Se}, \mathrm{Fe}$, and $\mathrm{Ni}$ elements on the surface of 3D NiFe alloy (Fig. 1d). TEM and HRTEM images (Fig. 1e and Figs. S4, S5) of $\mathrm{NiSe}_{2} / \mathrm{NiFe}_{2} \mathrm{Se}_{4} @ \mathrm{NiFe}$ displayed that the characteristic spacings of 0.30 and $0.27 \mathrm{~nm}$ are attributed to the (200) and (210) planes of $\mathrm{NiSe}_{2}$, while the characteristic distances of 0.34 and $0.23 \mathrm{~nm}$ are corresponded to the (011) and (211) planes of $\mathrm{NiFe}_{2} \mathrm{Se}_{4}$, respectively. Further, an obvious boundary of the crystal surface between $\mathrm{NiSe}_{2}$ and $\mathrm{NiFe}_{2} \mathrm{Se}_{4}$ was clearly observed (Fig. S6), successfully revealing the formed heterostructure of $\mathrm{NiSe}_{2} /$ $\mathrm{NiFe}_{2} \mathrm{Se}_{4} @ \mathrm{NiFe}$. SAED pattern showed the well-crystallized of $\mathrm{NiSe}_{2}$ and $\mathrm{NiFe}_{2} \mathrm{Se}_{4}$ in $\mathrm{NiSe}_{2} / \mathrm{NiFe}_{2} \mathrm{Se}_{4} @ \mathrm{NiFe}$ (inset of Fig. 1e) [36].

XRD of $\mathrm{NiSe}_{2} / \mathrm{NiFe}_{2} \mathrm{Se}_{4} @ \mathrm{NiFe}$ (Fig. S7) showed the characteristic diffraction peaks of $\mathrm{NiSe}_{2}$ (JPCDS No. 11-0552) and $\mathrm{NiFe}_{2} \mathrm{Se}_{4}$ (JPCDS No. 065-2338) [37]. The ratio of $\mathrm{NiSe}_{2}$ and $\mathrm{NiFe}_{2} \mathrm{Se}_{4}$ in the $\mathrm{NiSe}_{2} / \mathrm{NiFe}_{2} \mathrm{Se}_{4} @ \mathrm{NiFe}$ was determined to be $\sim 2.58$ according to inductively coupled X-ray fluorescence spectrometry. X-ray photoelectron spectroscopy (XPS) revealed the co-habiting of $\mathrm{Ni}$, $\mathrm{Fe}$, and Se elements in the $\mathrm{NiSe}_{2} / \mathrm{NiFe}_{2} \mathrm{Se}_{4}$ (Fig. S8). The 

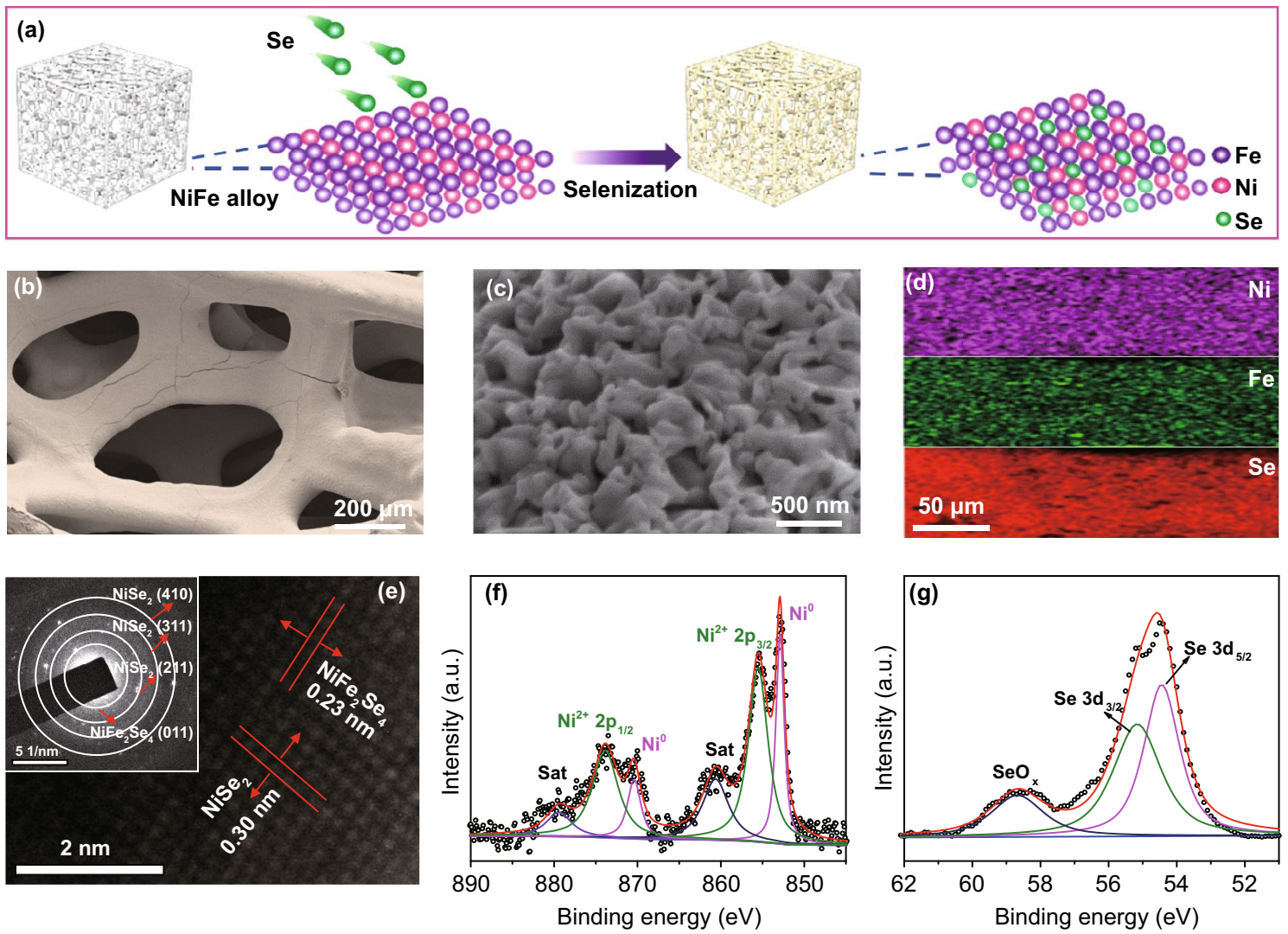

Fig. 1 a Schematic illustration for one-step fabrication strategy of $\mathrm{NiSe}_{2} / \mathrm{NiFe}_{2} \mathrm{Se}_{4} @ \mathrm{NiFe}$. b, c FESEM images of $\mathrm{NiSe} / \mathrm{NiFe} \mathrm{Se}_{4} @ \mathrm{NiFe}_{2} \mathbf{d}$ EDX elemental mappings images of $\mathrm{Ni}, \mathrm{Fe}$, and Se elements in $\mathrm{NiSe}_{2} / \mathrm{NiFe}_{2} \mathrm{Se}_{4} @ \mathrm{NiFe}$. e HRTEM image of $\mathrm{NiSe}_{2} / \mathrm{NiFe}_{2} \mathrm{Se}_{4} @ \mathrm{NiFe}$; inset: corresponding SAED pattern. High-resolution XPS spectra of $\mathbf{f} \mathrm{Ni} 2 p$ and $\mathbf{g} \mathrm{Se} 3 \mathrm{~d}$ for $\mathrm{NiSe}_{2} / \mathrm{NiFe}_{2} \mathrm{Se}_{4} @ \mathrm{NiFe}$

high-resolution Ni $2 p$ XPS spectra of $\mathrm{NiSe}_{2} / \mathrm{NiFe}_{2} \mathrm{Se}_{4} @$ $\mathrm{NiFe}$ heterostructure displayed two principal peaks located at 873.8 and $855.5 \mathrm{eV}$, which are corresponding to the $\mathrm{Ni}^{2+}$ $2 p_{1 / 2}$ and $\mathrm{Ni}^{2+} 2 p_{3 / 2}$ (Fig. 1f), associated with two satellite peaks. Relative to the pure $\mathrm{NiSe}_{2}[29,38]$, a slight shift of the principal peaks toward the higher binding energies was observed for $\mathrm{NiSe}_{2} / \mathrm{NiFe}_{2} \mathrm{Se}_{4} @ \mathrm{NiFe}$, which could be attributed to strongly coupled effects between $\mathrm{NiSe}_{2}$ and $\mathrm{NiFe}_{2} \mathrm{Se}_{4}$ in the heterostructure [39]. Furthermore, the binding energies centered at 852.9 and $870.3 \mathrm{eV}$ are corresponding to metallic $\mathrm{Ni}$ from the NiFe alloy. The high-resolution $\mathrm{Se} 3 d$ XPS spectra of $\mathrm{NiSe}_{2} / \mathrm{NiFe}_{2} \mathrm{Se}_{4} @ \mathrm{NiFe}$ exhibited three contributions, including two $\mathrm{Se} 3 d_{5 / 2}$ and Se $3 d_{3 / 2}$ peaks located at 54.5 and $55.2 \mathrm{eV}$, respectively, and one low and wide peak located at $58.6 \mathrm{eV}$ of $\mathrm{SeO}_{x}$ species (Fig. 1g) [40, 41]. It is important that, the $\mathrm{Se} 3 d$ peaks at 54.5 and $55.2 \mathrm{eV}$ are separately located between $54.0 \mathrm{eV}$ for $\mathrm{Se}^{2-}$ and $54.7 \mathrm{eV}$ for $\mathrm{Se}_{2}{ }^{2-}$ as well as between $54.9 \mathrm{eV}$ for $\mathrm{Se}^{2-}$ and $55.6 \mathrm{eV}$ for
$\mathrm{Se}_{2}{ }^{2-}$, suggesting the co-existence of $\mathrm{NiSe}_{2}$ and $\mathrm{NiFe}_{2} \mathrm{Se}_{4}$ [42].

\subsection{Electrocatalytic OER Performance}

The OER polarization curve of $\mathrm{NiSe}_{2} / \mathrm{NiFe}_{2} \mathrm{Se}_{4} @ \mathrm{NiFe}$ was first determined in $1.0 \mathrm{M} \mathrm{KOH}$ electrolyte. In comparison, the control samples of $\mathrm{Ni}$ foam@60 mg Se $300{ }^{\circ} \mathrm{C}$ (NF-Se), $\mathrm{Fe}$ foam@60 mg Se $300{ }^{\circ} \mathrm{C}$ (IF-Se), and Ir/C/NiFe were also tested. As shown in Fig. 2a, b, the $\mathrm{NiSe}_{2} / \mathrm{NiFe}_{2} \mathrm{Se}_{4} @$ $\mathrm{NiFe}$ exhibited admirable electrocatalytic activity with smaller potentials of $1.49,1.53$, and $1.54 \mathrm{~V}$ at current densities of 100,500 , and $1000 \mathrm{~mA} \mathrm{~cm}^{-2}$, compared with those of NF-Se and IF-Se. Significantly, the potential needed to drive a large current density up to $1500 \mathrm{~mA} \mathrm{~cm}^{-2}$ was only $1.56 \mathrm{~V}$, which makes the $\mathrm{NiSe}_{2} / \mathrm{NiFe}_{2} \mathrm{Se}_{4} @ \mathrm{NiFe}$ up-andcoming OER electrocatalyst towards industrial applications 
in alkaline water splitting. Meanwhile, the OER Faradaic efficiency of $\mathrm{NiSe}_{2} / \mathrm{NiFe}_{2} \mathrm{Se}_{4} @ \mathrm{NiFe}$ was calculated to be $\sim 100 \%$ (Fig. S9).

Comparison of the OER performances among $\mathrm{NiSe}_{2} /$ $\mathrm{NiFe}_{2} \mathrm{Se}_{4} @ \mathrm{NiFe}, \mathrm{NF}-\mathrm{Se}$, and IF-Se demonstrated the positive effects of the synergistic effect between $\mathrm{NiSe}_{2}$ and $\mathrm{NiFe}_{2} \mathrm{Se}_{4}$ components, which contributed to the superior OER activities of the $\mathrm{NiSe}_{2} / \mathrm{NiFe}_{2} \mathrm{Se}_{4} @ \mathrm{NiFe}$. Apparently, the OER catalytic activity of $\mathrm{NiSe}_{2} / \mathrm{NiFe}_{2} \mathrm{Se}_{4} @ \mathrm{NiFe}$ significantly surpassed that of the benchmark $\mathrm{Ir} / \mathrm{C} / \mathrm{NiFe}$, which showed high potentials of $1.53,1.60$, and $1.65 \mathrm{~V}$ at 100,500 , and $1000 \mathrm{~mA} \mathrm{~cm}^{-2}$, respectively. The Tafel slope of $\mathrm{NiSe}_{2} /$ $\mathrm{NiFe}_{2} \mathrm{Se}_{4} @ \mathrm{NiFe}$ was $52.7 \mathrm{dec}^{-1}$ (Fig. 2c), which was much smaller than the Tafel slopes of NF-Se (105.7 $\left.\mathrm{dec}^{-1}\right), \mathrm{Fe}-\mathrm{Se}$ (119.6 $\left.\mathrm{dec}^{-1}\right)$, and $\mathrm{Ir} / \mathrm{C} / \mathrm{NiFe}\left(96.4 \mathrm{mV} \mathrm{dec}{ }^{-1}\right)$, indicating a rapid reaction kinetic of the $\mathrm{NiSe}_{2} / \mathrm{NiFe}_{2} \mathrm{Se}_{4} @ \mathrm{NiFe}$. The OER kinetics of $\mathrm{NiSe}_{2} / \mathrm{NiFe}_{2} \mathrm{Se}_{4} @ \mathrm{NiFe}$ was further investigated by electrochemical impedance spectroscopy (EIS), and the Nyquist plots of the $\mathrm{NiSe}_{2} / \mathrm{NiFe}_{2} \mathrm{Se}_{4} @ \mathrm{NiFe}$ showed the much lower charge-transfer impedance as compared with that of NF-Se and IF-Se (Fig. 2d), supporting the fast electron transfer ability of $\mathrm{NiSe}_{2} / \mathrm{NiFe}_{2} \mathrm{Se}_{4} @ \mathrm{NiFe}$. The potential
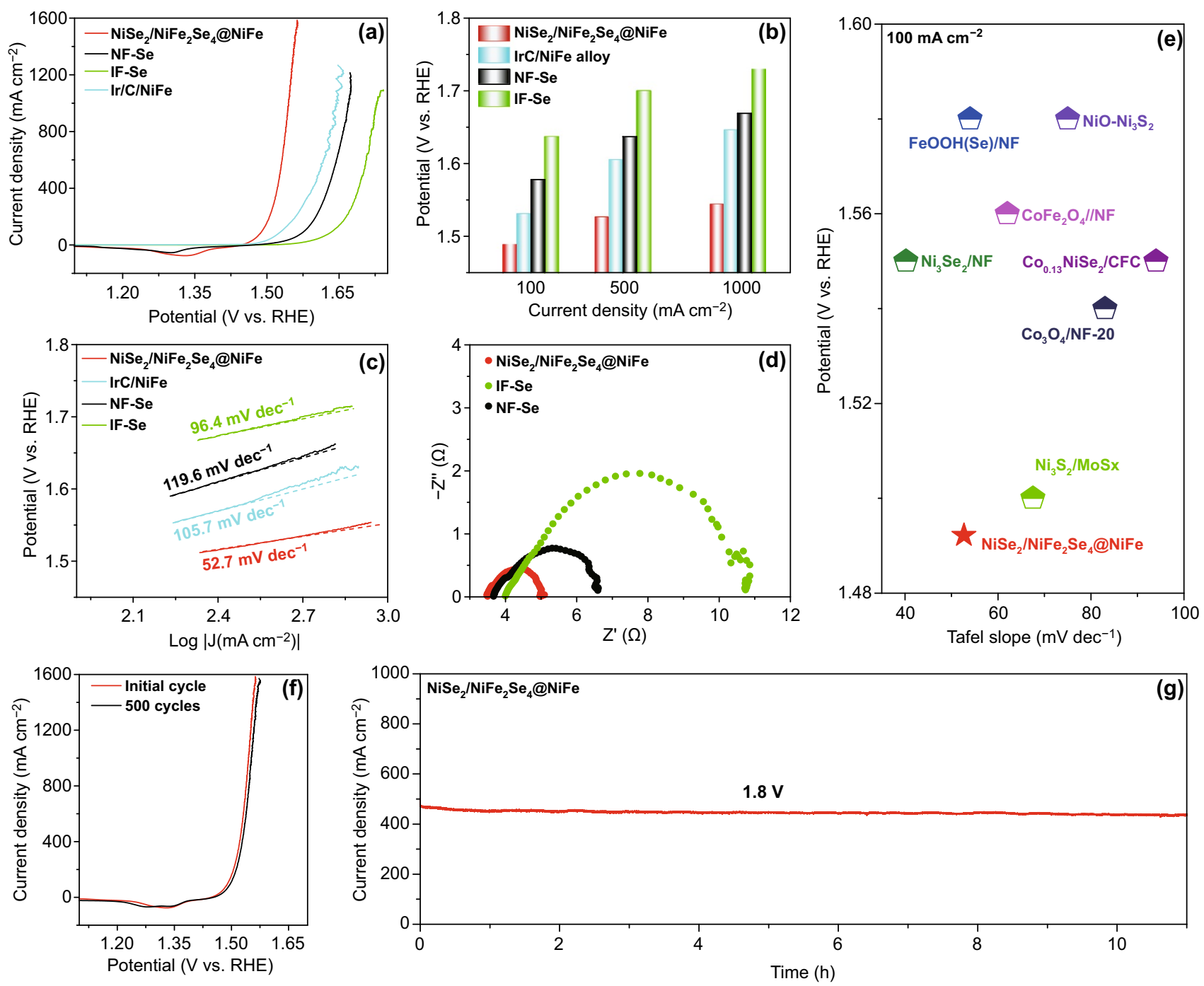

Fig. 2 a Polarization curves of $\mathrm{NiSe}_{2} / \mathrm{NiFe}_{2} \mathrm{Se}_{4} @ \mathrm{NiFe}, \mathrm{NF}-\mathrm{Se}$, IF-Se, and Ir/C/NiFe with iR compensation. b Comparison of potentials required at 100, 500, and $1000 \mathrm{~mA} \mathrm{~cm}{ }^{-2}$ for $\mathrm{NiSe}_{2} / \mathrm{NiFe}_{2} \mathrm{Se}_{4} @ \mathrm{NiFe}$, NF-Se, IF-Se, and Ir/C/NiFe. c Tafel plots of $\mathrm{NiSe}_{2} / \mathrm{NiFe}_{2} \mathrm{Se} \mathrm{N}_{4} @ \mathrm{NiFe}, \mathrm{NF}-\mathrm{Se}$, IF-Se, and Ir/C/NiFe. d Nyquist plots of $\mathrm{NiSe}_{2} / \mathrm{NiFe}_{2} \mathrm{Se}_{4} @ \mathrm{NiFe}, \mathrm{NF}-\mathrm{Se}$, and IF-Se. e Comparison of Tafel slopes and potentials required for $100 \mathrm{~mA} \mathrm{~cm}^{-2}$. f Polarization curves of $\mathrm{NiSe}_{2} / \mathrm{NiFe}_{2} \mathrm{Se}_{4} @ \mathrm{NiFe}$ before and after 500 cycles with iR compensation. g Chronoamperometry curve with the $\mathrm{NiSe}_{2} / \mathrm{NiFe}_{2} \mathrm{Se}_{4} @ \mathrm{NiFe}$ as electrode at $1.8 \mathrm{~V}$ without iR compensation. Electrolyte: $1.0 \mathrm{M} \mathrm{KOH}$ 
at $100 \mathrm{~mA} \mathrm{~cm}^{-2}$ and corresponding Tafel slope of $\mathrm{NiSe}_{2} /$ $\mathrm{NiFe}_{2} \mathrm{Se}_{4} @ \mathrm{NiFe}$ were appreciably superior than that of those previously reported $\mathrm{Ni} / \mathrm{Fe}$-based selenides and other nonprecious OER electrocatalysts in $1.0 \mathrm{M} \mathrm{KOH} \mathrm{(Fig.} \mathrm{2e} \mathrm{and}$ Table S1) [6, 40, 43-47].

Figure S10 shows a multi-step chronopotentiometric curve of $\mathrm{NiSe}_{2} / \mathrm{NiFe}_{2} \mathrm{Se}_{4} @ \mathrm{NiFe}$, in which the starting current density was $380 \mathrm{~mA} \mathrm{~cm}^{-2}$ at $1.67 \mathrm{~V}$, and remained unchanged for the rest $100 \mathrm{~s}$; the other four steps also exhibited parallel results up to $1180 \mathrm{~mA} \mathrm{~cm}{ }^{-2}$, suggesting the remarkable mass transport properties and mechanical toughness of $\mathrm{NiSe}_{2} / \mathrm{NiFe}_{2} \mathrm{Se}_{4} @ \mathrm{NiFe}[48,49]$. As the durability is another effective standard to assess the electrocatalytic ability of $\mathrm{NiSe}_{2} / \mathrm{NiFe}_{2} \mathrm{Se}_{4} @ \mathrm{NiFe}$, continuous electrochemical cycling tests were performed for 500 cycles. In Fig. $2 f$, the $\mathrm{NiSe}_{2} / \mathrm{NiFe}_{2} \mathrm{Se}_{4} @ \mathrm{NiFe}$ exhibited permanent stability with a minor current loss at the end of cycling. Further, the $\mathrm{NiSe}_{2} /$ $\mathrm{NiFe}_{2} \mathrm{Se}_{4} @ \mathrm{NiFe}$ also owned long-term durability with an insignificant recession during consecutive current output at $500 \mathrm{~mA} \mathrm{~cm}^{-2}$ over $11 \mathrm{~h}$ (Fig. $2 \mathrm{~g}$ ).

In order to identify the synergistic effect of bimetallic selenide heterostructure towards the extrusive OER performance, we measured double-layer capacitance $\left(C_{\mathrm{dl}}\right)$ to evaluate the electrochemical surface area (ECSA) of 3D NiSe $2 /$ $\mathrm{NiFe}_{2} \mathrm{Se}_{4} @ \mathrm{NiFe}$. As shown in Fig. 3a and Fig. S11, the $C_{\mathrm{dl}}$ of $33.67 \mathrm{mF} \mathrm{cm}{ }^{-2}$ for $\mathrm{NiSe}_{2} / \mathrm{NiFe}_{2} \mathrm{Se}_{4} @ \mathrm{NiFe}$ was much higher than $16.48 \mathrm{mF} \mathrm{cm}^{-2}$ for NF-Se and $5.09 \mathrm{mF} \mathrm{cm}^{-2}$ for IF-Se, illustrating that the $\mathrm{NiSe}_{2} / \mathrm{NiFe}_{2} \mathrm{Se}_{4} @ \mathrm{NiFe}$ possessed an extraordinary activity with larger ECSA and more accessible active sites as compared with the NF-Se and IF-Se. For clarification of the inherent OER activity of $3 \mathrm{D} \mathrm{NiSe} \mathrm{NiFe}_{2} \mathrm{Se}_{4} @ \mathrm{NiFe}$, the polarization curve of the heterostructure electrode was further normalized by ECSA (Fig. 3b), and the results displayed that the intrinsic activity of $\mathrm{NiSe}_{2} / \mathrm{NiFe}_{2} \mathrm{Se}_{4} @ \mathrm{NiFe}$ was still much higher than that of NF-Se and IF-Se [50, 51]. In order to further
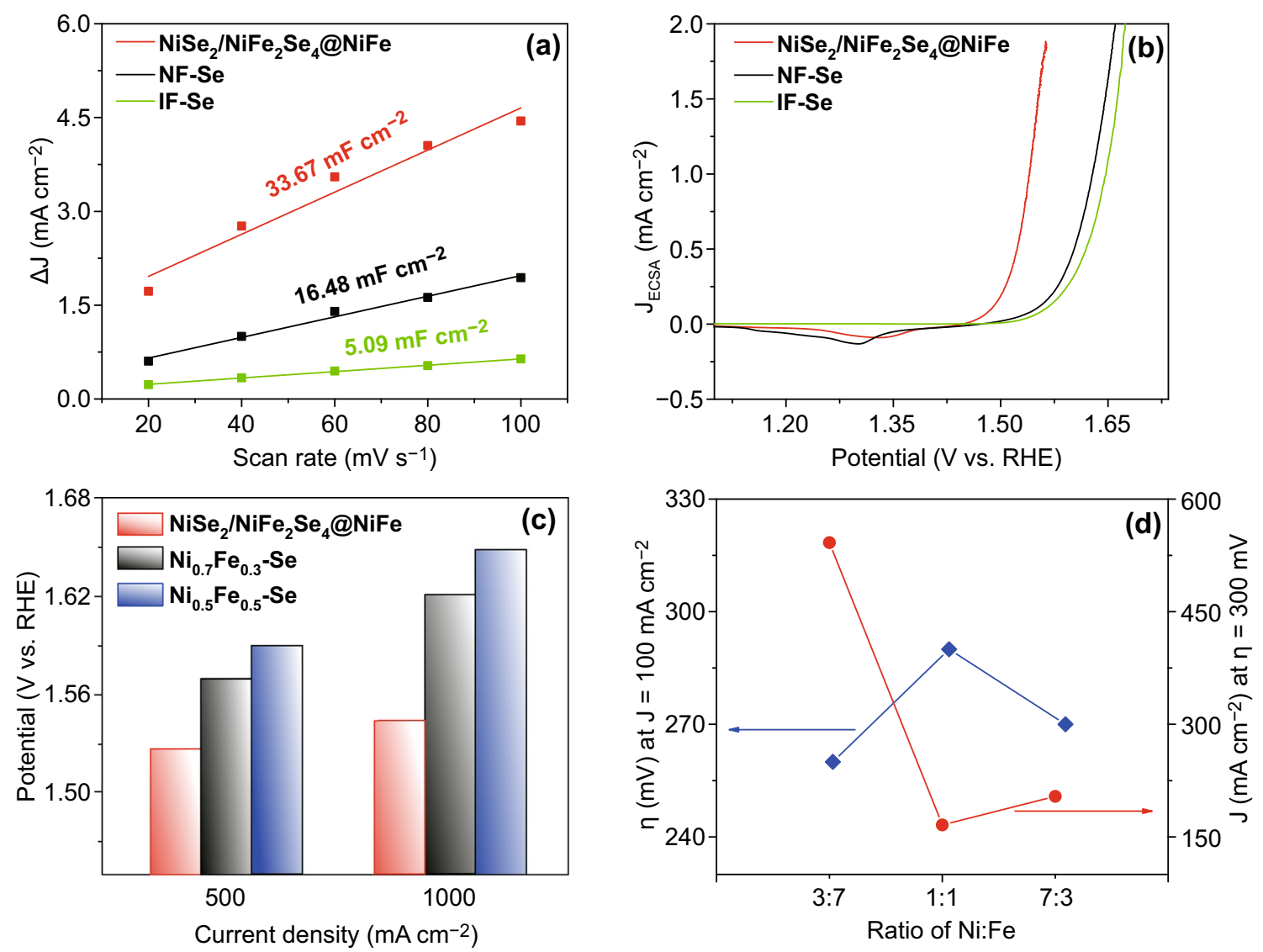

Fig. 3 a ECSAs and b ECSA-normalized polarization curves of $\mathrm{NiSe}_{2} / \mathrm{NiFe}_{2} \mathrm{Se}_{4} @ \mathrm{NiFe}, \mathrm{NF}-\mathrm{Se}$, and IF-Se. c Comparison of potentials required at 500 and $1000 \mathrm{~mA} \mathrm{~cm}{ }^{-2}$ for $\mathrm{NiSe}_{2} / \mathrm{NiFe}_{2} \mathrm{Se}_{4} @ \mathrm{NiFe}, \mathrm{Ni}_{0.7} \mathrm{Fe}_{0.3}-\mathrm{Se}$, and $\mathrm{Ni}_{0.5} \mathrm{Fe}_{0.5}-\mathrm{Se}$. d OER activities of $\mathrm{NiSe}_{2} / \mathrm{NiFe}_{2} \mathrm{Se}_{4} @ \mathrm{NiFe} \mathrm{Ni}_{0.7} \mathrm{Fe}_{0.3}-$ $\mathrm{Se}$, and $\mathrm{Ni}_{0.5} \mathrm{Fe}_{0.5}-\mathrm{Se}$ at $100 \mathrm{~mA} \mathrm{~cm}{ }^{-2}$ and $300 \mathrm{mV}$ 
investigate the influence of $\mathrm{Ni}$ : Fe ratios, we additionally constructed other catalytic materials of $\mathrm{Ni}_{0.5} \mathrm{Fe}_{0.5} @ 60 \mathrm{mg}$ Se $300{ }^{\circ} \mathrm{C}\left(\mathrm{Ni}_{0.5} \mathrm{Fe}_{0.5}-\mathrm{Se}\right)$ and $\mathrm{Ni}_{0.7} \mathrm{Fe}_{0.3} @ 60 \mathrm{mg} \mathrm{Se} 300{ }^{\circ} \mathrm{C}$ $\left(\mathrm{Ni}_{0.7} \mathrm{Fe}_{0.3}-\mathrm{Se}\right)$ with different $\mathrm{Ni} / \mathrm{Fe}$ proportions. As shown in Fig. 3c, d and Fig. S12, the OER performances of the $\mathrm{NiSe}_{2} / \mathrm{NiFe}_{2} \mathrm{Se}_{4} @ \mathrm{NiFe}, \mathrm{Ni}_{0.5} \mathrm{Fe}_{0.5}-\mathrm{Se}$, and $\mathrm{Ni}_{0.7} \mathrm{Fe}_{0.3}-\mathrm{Se}$ displayed that the potentials of $\mathrm{Ni}_{0.5} \mathrm{Fe}_{0.5}-\mathrm{Se}$ and $\mathrm{Ni}_{0.7} \mathrm{Fe}_{0.3}-\mathrm{Se}$ were 1.59 and $1.57 \mathrm{~V}$ at $500 \mathrm{~mA} \mathrm{~cm}^{-2}$, which are significantly larger than that of the $\mathrm{NiSe}_{2} / \mathrm{NiFe}_{2} \mathrm{Se}_{4} @ \mathrm{NiFe}(1.53 \mathrm{~V}$ at $500 \mathrm{~mA} \mathrm{~cm}^{-2}$ ). Also, when the overpotential was fixed at $300 \mathrm{mV}$, the current densities of both $\mathrm{Ni}_{0.5} \mathrm{Fe}_{0.5}-\mathrm{Se}$ and $\mathrm{Ni}_{0.7} \mathrm{Fe}_{0.3}-\mathrm{Se}$ were 166 and $204 \mathrm{~mA} \mathrm{~cm}{ }^{-2}$ (Fig. 3d), extremely smaller than that of $\mathrm{NiSe}_{2} / \mathrm{NiFe}_{2} \mathrm{Se}_{4} @ \mathrm{NiFe}$ $\left(542 \mathrm{~mA} \mathrm{~cm}{ }^{-2}\right)$. These results indicated that the $\mathrm{NiSe}_{2} /$ $\mathrm{NiFe}_{2} \mathrm{Se}_{4} @ \mathrm{NiFe}$ with a Ni/Fe ratio of 3:7 possessed the optimized OER activity in comparison with $\mathrm{Ni}_{0.5} \mathrm{Fe}_{0.5}-\mathrm{Se}$ and $\mathrm{Ni}_{0.7} \mathrm{Fe}_{0.3}-\mathrm{Se}$ [52].

\subsection{Identifying Active Phase}

The structural change of $\mathrm{NiSe}_{2} / \mathrm{NiFe}_{2} \mathrm{Se}_{4} @ \mathrm{NiFe}$ during the OER process was analyzed by in-situ electrochemical Raman spectroscopy at different applied potentials in 1.0 M KOH (Fig. 4a). At a voltage of $1.0 \mathrm{~V}$, the Raman peaks of $\mathrm{NiSe}_{2} / \mathrm{NiFe}_{2} \mathrm{Se}_{4} @ \mathrm{NiFe}$ located at 152, 170, 205, and $237 \mathrm{~cm}^{-1}$ could be assigned to $\mathrm{NiSe}_{2}$ (Fig. 4b, c); it was clearly seen that the Raman peaks of $\mathrm{NiSe}_{2}$ gradually weakened with the increased voltage. After the OER tests (Fig. 4d), no Raman peaks of $\mathrm{NiSe}_{2}$ were detected, but new distinctive peaks associated with the unique Raman features of amorphous $\mathrm{FeOOH}$ and $\mathrm{NiOOH}$ species could be observed, which indicated that the amorphous $\mathrm{FeOOH}$ and $\mathrm{NiOOH}$ phases are the catalytically active phases of $\mathrm{NiSe}_{2} / \mathrm{NiFe}_{2} \mathrm{Se}_{4} @ \mathrm{NiFe}$ during the OER process $[39,53]$. Such features are also consistence well with post-HRTEM observations (Fig. S13). The chemical valence states of $\mathrm{NiSe}_{2} / \mathrm{NiFe}_{2} \mathrm{Se}_{4} @ \mathrm{NiFe}$ before and after OER tests were measured by XPS spectra. After 11 h OER stability testing, in the high-resolution XPS spectra of Ni $2 p$ (Fig. 4e), the binding energy of metallic $\mathrm{Ni}$ disappeared, and the binding energies of $\mathrm{Ni}^{3+} 2 p_{3 / 2}$ and $\mathrm{Ni}^{3+} 2 p_{1 / 2}$ emerged and located at 856.4 and $874.5 \mathrm{eV}$, which indicated the oxidation of $\mathrm{Ni}^{2+}$ to $\mathrm{Ni}^{3+}$ [54]. For the high-resolution
XPS spectra of Fe $2 p$ (Fig. 4f), four main peaks located at 710.7, 713.2, 724.6, and $728.7 \mathrm{eV}$ were corresponded well with $\mathrm{Fe}^{2+} 2 p_{3 / 2}, \mathrm{Fe}^{3+} 2 p_{3 / 2}, \mathrm{Fe}^{2+} 2 p_{1 / 2}$, and $\mathrm{Fe}^{3+} 2 p_{1 / 2}$, respectively. After the OER tests, two new Fe $2 p_{3 / 2}$ peaks appeared at 711.7 and $725.1 \mathrm{eV}$, respectively, which are the characteristic binding energies of $\mathrm{Fe}^{3+}$ in $\mathrm{FeOOH}$ [1]. These results demonstrated that the in-situ derived amorphous $\mathrm{FeOOH}$ and $\mathrm{NiOOH}$ phases serve as OER active centers in $\mathrm{NiSe}_{2} / \mathrm{NiFe}_{2} \mathrm{Se}_{4} @ \mathrm{NiFe}$ during the OER process, which was in accord with the Raman results. Based on the above results, a possible mechanism of the OER electrocatalysis in alkaline electrolyte has been considerate as follows $[43,55,56]$ :

$\mathrm{M}_{\text {cat }}+\mathrm{OH}^{-} \rightarrow \mathrm{M}_{\text {cat }} \mathrm{OH}_{\mathrm{ad}}+\mathrm{e}^{-}$

$\mathrm{M}_{\text {cat }} \mathrm{OH}_{\mathrm{ad}}+\mathrm{OH}^{-} \rightarrow \mathrm{M}_{\text {cat }} \mathrm{O}_{\mathrm{ad}}+\mathrm{H}_{2} \mathrm{O}+\mathrm{e}^{-}$

$\mathrm{M}_{\text {cat }} \mathrm{O}_{\mathrm{ad}}+\mathrm{OH}^{-} \rightarrow \mathrm{M}_{\text {cat }} \mathrm{OOH}_{\mathrm{ad}}+\mathrm{e}^{-}$

$\mathrm{M}_{\text {cat }} \mathrm{OOH}_{\mathrm{ad}}+\mathrm{OH}^{-} \rightarrow \mathrm{M}_{\text {cat }}+\mathrm{O}_{2}+\mathrm{H}_{2} \mathrm{O}+\mathrm{e}^{-}$

where the $\mathrm{NiOOH}$ and $\mathrm{FeOOH}$ species were firstly formed on the surface of $\mathrm{NiSe}_{2} / \mathrm{NiFe}_{2} \mathrm{Se}_{4} @ \mathrm{NiFe}$ accessed by $\mathrm{OH}^{-}$in alkaline electrolyte. Then, the formed $\mathrm{NiOOH}$ and $\mathrm{FeOOH}$ phases were further combined with the $\mathrm{OH}^{-}$to generate $\mathrm{O}_{2}$ under OER conditions $(\mathrm{M}=\mathrm{Ni}, \mathrm{Fe})$ [57-60].

Considering that the $\mathrm{O}_{2}$ bubbles generated under the harsh electrochemical conditions tend to decrease the surface roughness and limit electron transfer, the contact wetting angle of $\mathrm{NiSe}_{2} / \mathrm{NiFe}_{2} \mathrm{Se}_{4} @ \mathrm{NiFe}$ was measured (Fig. $4 \mathrm{~g}-\mathrm{j}$ ). The results showed that the generated $\mathrm{O}_{2}$ bubbles are separated in an ultra-fast speed from the surface, indicating a "superaerophobic" feature. The unique "superaerophobic" structure of $\mathrm{NiSe}_{2} / \mathrm{NiFe}_{2} \mathrm{Se}_{4} @ \mathrm{NiFe}$ could deliver a huge potential to release the in-situ generated $\mathrm{O}_{2}$ bubbles and avoid the bubbles to be detented during the OER process, thus retaining the original catalytic sites of $\mathrm{NiSe}_{2} / \mathrm{NiFe}_{2} \mathrm{Se}_{4} @ \mathrm{NiFe}$. Therefore, besides the $\mathrm{FeOOH}$ and $\mathrm{NiOOH}$ active phases, the unique "superaerophobic" property of $\mathrm{NiSe}_{2} / \mathrm{NiFe}_{2} \mathrm{Se}_{4} @ \mathrm{NiFe}$ that can expel the in-situ generated $\mathrm{O}_{2}$ bubbles also make a contribution to the high-efficient OER activity and excellent stability at high current densities [61]. 

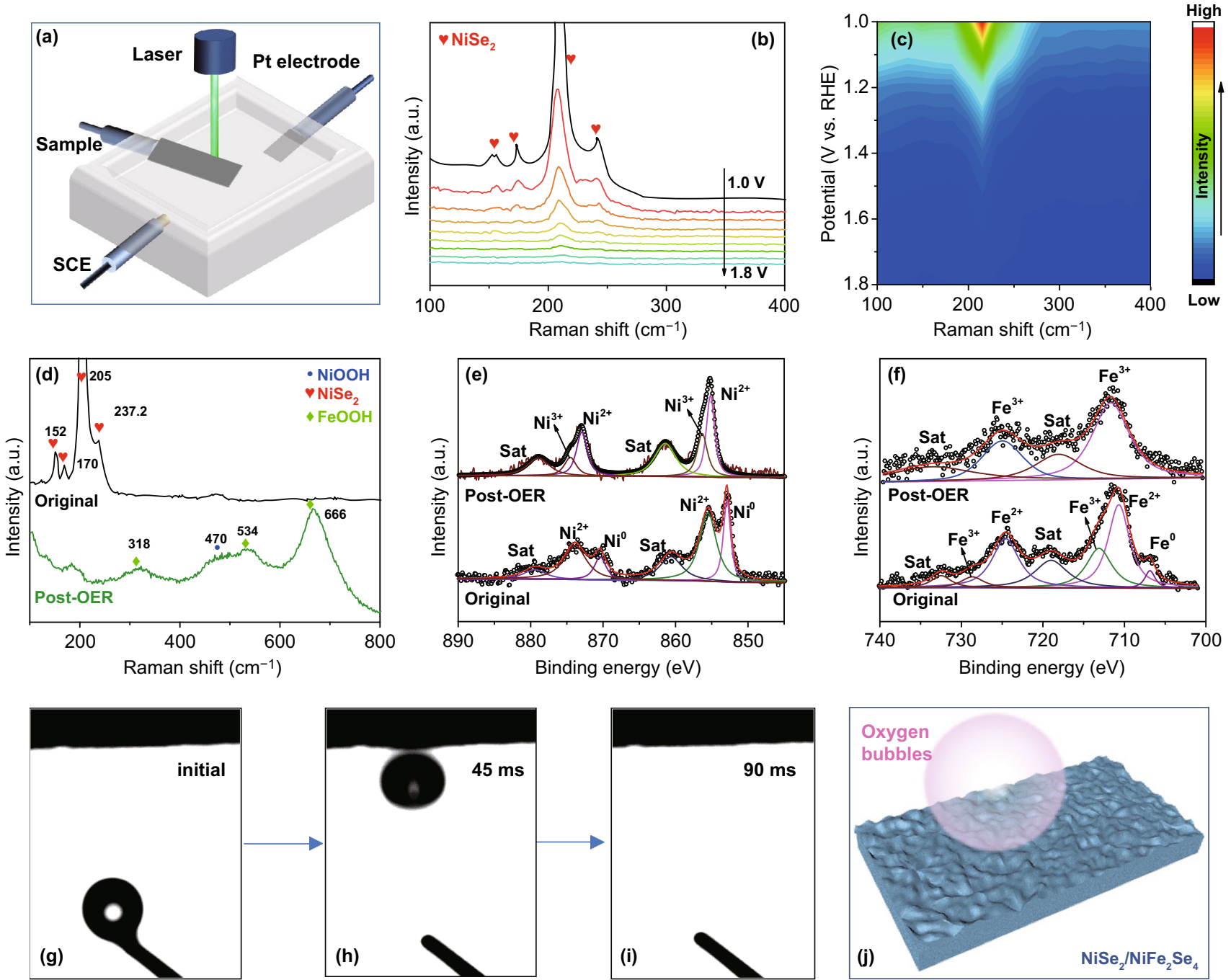

Fig. 4 a Digital images of in-situ electrochemical Raman spectroscopy for $\mathrm{NiSe}_{2} / \mathrm{NiFe}_{2} \mathrm{Se}_{4} @ \mathrm{NiFe}$ during OER process. b In-situ Raman spectra and c corresponding contour plots of $\mathrm{NiSe}_{2} / \mathrm{NiFe}_{2} \mathrm{Se}_{4} @ \mathrm{NiFe}$ at various potentials. d Raman spectra of $\mathrm{NiSe}_{2} / \mathrm{NiFe}_{2} \mathrm{Se}_{4} @ \mathrm{NiFe}$ before and after OER tests. e, f High-resolution Ni $2 p$ and Fe $2 p$ XPS spectra of $\mathrm{NiSe}_{2} / \mathrm{NiFe}_{2} \mathrm{Se}_{4} @ \mathrm{NiFe}$ before and after OER tests. g-i Digital images of $\mathrm{O}_{2}$ bubbles on $\mathrm{NiSe}_{2} / \mathrm{NiFe}_{2} \mathrm{Se}_{4} @ \mathrm{NiFe}$. j Schematic illustration of the adhesion behavior for $\mathrm{O}_{2}$ bubbles on $\mathrm{NiSe}_{2} / \mathrm{NiFe}_{2} \mathrm{Se}_{4} @ \mathrm{NiFe}$

\subsection{Overall-Water-Splitting Performance}

Based on the outstanding OER performances, the 3D NiSe 2 $\mathrm{NiFe}_{2} \mathrm{Se}_{4} @ \mathrm{NiFe}$ were applied as both anode and cathode for the testing of overall-water-splitting. The $\mathrm{NiSe}_{2} / \mathrm{NiFe}_{2} \mathrm{Se}_{4} @$ $\mathrm{NiFe}$ exhibited a bifunctional electrocatalytic performance in overall-water-splitting, which only needed cell voltages of 2.32 and $2.82 \mathrm{~V}$ to reach high current densities of 500 and $1000 \mathrm{~mA} \mathrm{~cm}^{-2}$ in $1.0 \mathrm{M} \mathrm{KOH}$, respectively. Notably, such a high overall-water-splitting performance for $\mathrm{NiSe}_{2} /$ $\mathrm{NiFe}_{2} \mathrm{Se}_{4} @ \mathrm{NiFe}$ was even superior to that of precious metal catalysts of $\mathrm{Ir} / \mathrm{C}$ anode and $\mathrm{Pt} / \mathrm{C}$ cathode with larger cell voltages of 2.56 and $>3.0 \mathrm{~V}$ at 500 and $1000 \mathrm{~mA} \mathrm{~cm}{ }^{-2}$ (Fig. 5a), respectively. Furthermore, the long-term stability of $\mathrm{NiSe}_{2} / \mathrm{NiFe}_{2} \mathrm{Se}_{4} @ \mathrm{NiFe}$ in electrochemical overallwater-splitting was confirmed with a high current density at $1000 \mathrm{~mA} \mathrm{~cm}^{-2}$ for $>10 \mathrm{~h}$ (Fig. 5b). As required for an industrial use, we further made an alkaline electrolyzer for overall-water-splitting using the bifunctional $\mathrm{NiSe}_{2} /$ $\mathrm{NiFe}_{2} \mathrm{Se}_{4} @ \mathrm{NiFe}$ in $10.0 \mathrm{M} \mathrm{KOH}$ at 25 and $60^{\circ} \mathrm{C}$. As shown in Fig. 5c, the $\mathrm{NiSe}_{2} / \mathrm{NiFe}_{2} \mathrm{Se}_{4} @ \mathrm{NiFe}$ delivered the higher overall-water-splitting performance at $60{ }^{\circ} \mathrm{C}(2.17 \mathrm{~V}$ at $1000 \mathrm{~mA} \mathrm{~cm}^{-2}$ ) than that at $25{ }^{\circ} \mathrm{C}$ [62]. Furthermore, the $\mathrm{NiSe}_{2} / \mathrm{NiFe}_{2} \mathrm{Se}_{4} @ \mathrm{NiFe}$ sustained durable stability with a low 

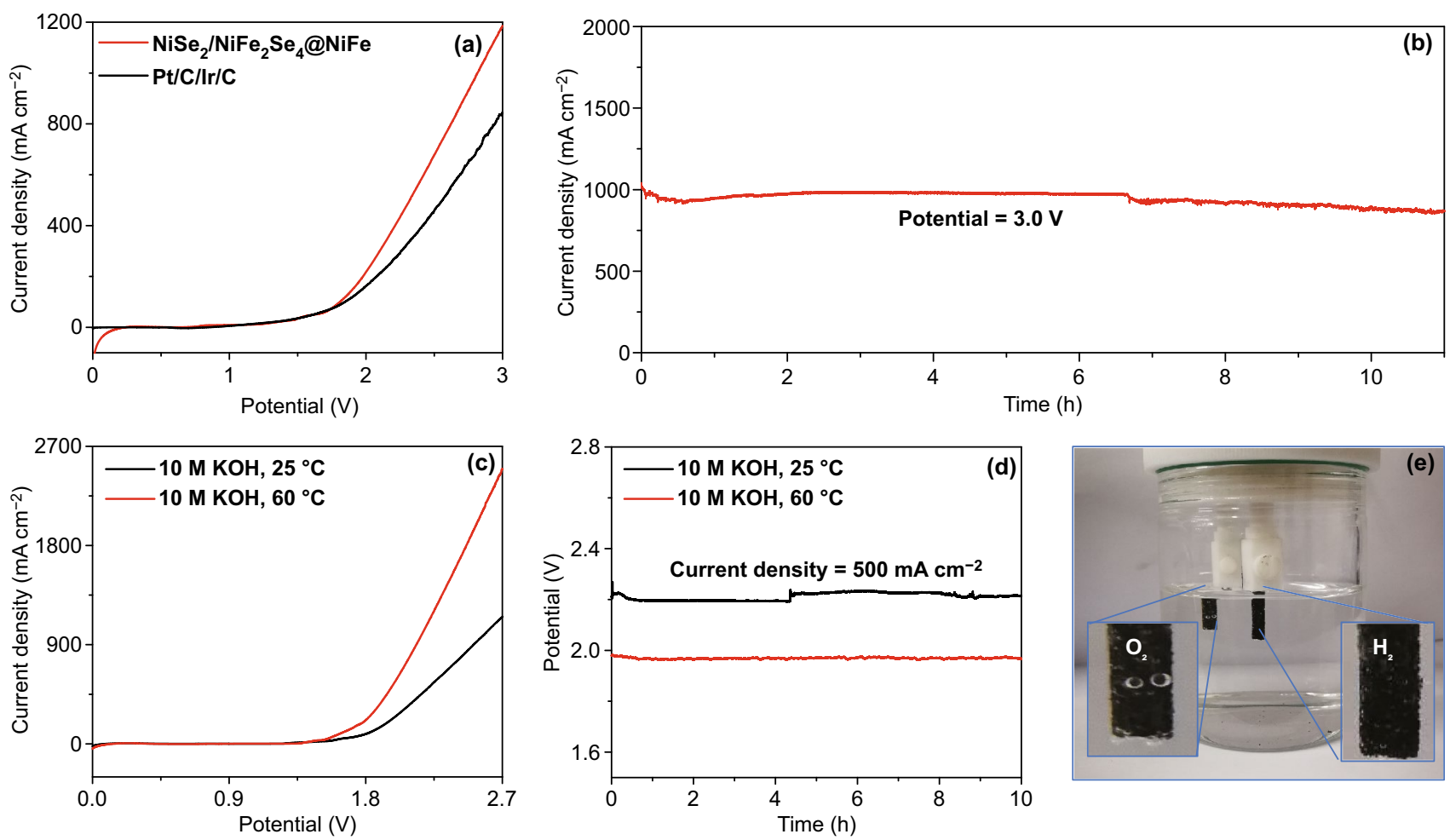

Fig. 5 a Polarization curves of bifunctional $\mathrm{NiSe}_{2} / \mathrm{NiFe}_{2} \mathrm{Se}_{4} @ \mathrm{NiFe}$ and $\mathrm{Pt} / \mathrm{C}$-Ir/C for overall-water-splitting. b Chronoamperometric measurement at $3.0 \mathrm{~V}$ across $\mathrm{NiSe}_{2} / \mathrm{NiFe}_{2} \mathrm{Se}_{4} @ \mathrm{NiFe}$ without iR compensation. c Polarization curves of bifunctional $\mathrm{NiSe}_{2} / \mathrm{NiFe}_{2} \mathrm{Se}_{4} @ \mathrm{NiFe}$ for overallwater-splitting in $10.0 \mathrm{M} \mathrm{KOH}$ at 25 and $60{ }^{\circ} \mathrm{C}$. d Chronopotentiometric curves with bifunctional $\mathrm{NiSe}_{2} / \mathrm{NiFe}_{2} \mathrm{Se}_{4} @ \mathrm{NiFe}$ in $10.0 \mathrm{M} \mathrm{KOH}$ at 25 and $60{ }^{\circ} \mathrm{C}$ at $500 \mathrm{~mA} \mathrm{~cm}{ }^{-2}$ without $i R$ compensation. e Digital image of the generated $\mathrm{H}_{2}$ and $\mathrm{O}_{2}$ gas on $\mathrm{NiSe}_{2} / \mathrm{NiFe}_{2} \mathrm{Se}_{4} @ \mathrm{NiFe}$

voltage of $1.96 \mathrm{~V}$ to achieve $500 \mathrm{~mA} \mathrm{~cm}^{-2}$ in $10.0 \mathrm{M} \mathrm{KOH}$ at $60{ }^{\circ} \mathrm{C}$ after chronoamperometry testing (Fig. 5d). During the testing process, the generated $\mathrm{O}_{2}$ and $\mathrm{H}_{2}$ bubbles are in-situ produced on the bifunctional $\mathrm{NiSe}_{2} / \mathrm{NiFe}_{2} \mathrm{Se}_{4} @$ $\mathrm{NiFe}$ (Fig. 5e), evidencing the favorable overall-water-splitting performance. These results suggested that the $\mathrm{NiSe}_{2} /$ $\mathrm{NiFe}_{2} \mathrm{Se}_{4} @ \mathrm{NiFe}$ could satisfy the industrial criteria for overall-water-splitting electrocatalysis.

\section{Conclusions}

A novel superaerophobic 3D NiSe $2 / \mathrm{NiFe}_{2} \mathrm{Se}_{4} @ \mathrm{NiFe}$ heterostructure composing of $\mathrm{NiSe}_{2}$ and $\mathrm{NiFe}_{2} \mathrm{Se}_{4}$ nanowrinkles was developed by a thermal selenization procedure. The $\mathrm{NiSe}_{2} / \mathrm{NiFe}_{2} \mathrm{Se}_{4} @ \mathrm{NiFe}$ showed excellent OER performance evidenced by outputting high current densities of 500 and $1000 \mathrm{~mA} \mathrm{~cm}^{-2}$ at low potentials of 1.53 and $1.54 \mathrm{~V}$ under alkaline condition, respectively, which are superior to those of most previously reported $\mathrm{Ni} / \mathrm{Fe}$-based selenides, even outperforming the commercial Ir/C. The excellent OER performance of $\mathrm{NiSe}_{2} / \mathrm{NiFe}_{2} \mathrm{Se}_{4} @ \mathrm{NiFe}$ to a large extent was due to the large active surface area and high electronic conductivity. The in-situ conversion-derived $\mathrm{FeOOH}$ and $\mathrm{NiOOH}$ species from the $\mathrm{NiSe}_{2} / \mathrm{NiFe}_{2} \mathrm{Se}_{4} @ \mathrm{NiFe}$ are intrinsic active sites for the OER catalysis. The unique "superaerophobic" structure of $\mathrm{NiSe}_{2} / \mathrm{NiFe}_{2} \mathrm{Se}_{4} @ \mathrm{NiFe}$ further promoted the rapid release of in-situ formed $\mathrm{O}_{2}$ bubbles in a superfast speed. The $\mathrm{NiSe}_{2} / \mathrm{NiFe}_{2} \mathrm{Se}_{4} @ \mathrm{NiFe}$ heterostructure required a low voltage of $2.17 \mathrm{~V}$ to attain $1000 \mathrm{~mA} \mathrm{~cm}^{-2}$ in $10.0 \mathrm{M}$ $\mathrm{KOH}$ electrolyte for overall-water-splitting at $60{ }^{\circ} \mathrm{C}$ meeting the requirement for industrial use. Therefore, the $\mathrm{NiSe}_{2} /$ $\mathrm{NiFe}_{2} \mathrm{Se}_{4} @ \mathrm{NiFe}$ heterostructure presented in this work may provide a promising way to synthesize superaerophobic bimetallic selenides towards the practical applications for clean hydrogen production, as well as the electrochemical $\mathrm{CO}_{2}$ reduction, $\mathrm{O}_{2}$ reduction, and $\mathrm{N}_{2}$ reduction reactions.

Acknowledgements This work was financially supported by the National Natural Science Foundation of China (21922811, 51702284, and 21878270), Zhejiang Provincial Natural Science 
Foundation of China (LR19B060002), and the Startup Foundation for Hundred-Talent Program of Zhejiang University. We thank the Zhiyan Pan, and Yangjun Jin (Environmental Chemical and Resource Research Institute, College of Environment, Zhejiang University of Technology) for Raman measurements. Hanqing Wang acknowledges support from Zhejiang Province Hangzhou No. 14 High School (Hangzhou, China).

Open Access This article is licensed under a Creative Commons Attribution 4.0 International License, which permits use, sharing, adaptation, distribution and reproduction in any medium or format, as long as you give appropriate credit to the original author(s) and the source, provide a link to the Creative Commons licence, and indicate if changes were made. The images or other third party material in this article are included in the article's Creative Commons licence, unless indicated otherwise in a credit line to the material. If material is not included in the article's Creative Commons licence and your intended use is not permitted by statutory regulation or exceeds the permitted use, you will need to obtain permission directly from the copyright holder. To view a copy of this licence, visit http://creativecommons.org/licenses/by/4.0/.

Electronic supplementary material The online version of this article (https://doi.org/10.1007/s40820-020-00442-0) contains supplementary material, which is available to authorized users.

\section{References}

1. H. Liang, A.N. Gandi, C. Xia, M.N. Hedhili, D.H. Anjum, U. Schwingenschlögl, H.N. Alshareef, Amorphous NiFe$\mathrm{OH} / \mathrm{NiFeP}$ electrocatalyst fabricated at low temperature for water oxidation applications. ACS Energy Lett. 2, 1035-1042 (2017). https://doi.org/10.1021/acsenergylett.7b00206

2. Y.Z. Xu, C.Z. Yuan, X.P. Chen, Co-Doped NiSe nanowires on nickel foam via a cation exchange approach as efficient electrocatalyst for enhanced oxygen evolution reaction. RSC Adv. 6, 106832-106836 (2016). https://doi.org/10.1039/C6RA2 $3580 \mathrm{H}$

3. H. Zhou, F. Yu, J. Sun, R. He, S. Chen, C.W. Chu, Z. Ren, Highly active catalyst derived from a $3 \mathrm{D}$ foam of $\mathrm{Fe}\left(\mathrm{PO}_{3}\right)_{2} /$ $\mathrm{Ni}_{2} \mathrm{P}$ for extremely efficient water oxidation. Proc. Natl. Acad. Sci. USA 114, 5607-5611 (2017). https://doi.org/10.1073/ pnas. 1701562114

4. J. Ke, M. Adnan Younis, Y. Kong, H. Zhou, J. Liu, L. Lei, Y. Hou, Nanostructured ternary metal tungstate-based photocatalysts for environmental purification and solar water splitting: a review. Nano-Micro Lett. 10, 69 (2018). https://doi. org/10.1007/s40820-018-0222-4

5. Y. Hou, X. Zhuang, X. Feng, Recent advances in earth-abundant heterogeneous electrocatalysts for photoelectrochemical water splitting. Small Methods 1, 1700090 (2017). https://doi. org/10.1002/smtd.201700090

6. L.M. Cao, Y.W. Hu, S.F. Tang, A. Iljin, J.W. Wang, Z.M. Zhang, T.B. Lu, Fe-CoP electrocatalyst derived from a bimetallic prussian blue analogue for large-current-density oxygen evolution and overall water splitting. Adv. Sci. 5, 1800949 (2018). https://doi.org/10.1002/advs.201800949

7. Y. Du, M. Zhang, Z. Wang, Y. Liu, Y. Liu, Y. Geng, L. Wang, A self-templating method for metal-organic frameworks to construct multi-shelled bimetallic phosphide hollow microspheres as highly efficient electrocatalysts for hydrogen evolution reaction. J. Mater. Chem. A 7, 8602-8608 (2019). https:// doi.org/10.1039/C9TA00557A

8. F. Zhang, Y. Ge, H. Chu, P. Dong, R. Baines, Y. Pei, M. Ye, J. Shen, Dual-functional starfish-like P-doped Co-Ni-S nanosheets supported on nickel foams with enhanced electrochemical performance and excellent stability for overall water splitting. ACS Appl. Mater. Interfaces 10, 7087-7095 (2018). https://doi.org/10.1021/acsami.7b18403

9. X. Shi, H. Wang, P. Kannan, J. Ding, S. Ji, F. Liu, H. Gai, R. Wang, Rich-grain-boundary of $\mathrm{Ni}_{3} \mathrm{Se}_{2}$ nanowire arrays as multifunctional electrode for electrochemical energy storage and conversion applications. J. Mater. Chem. A 7, 3344-3352 (2019). https://doi.org/10.1039/C8TA10912E

10. J. Yu, C. Lv, L. Zhao, L. Zhang, Z. Wang, Q. Liu, Reverse microemulsion-assisted synthesis of $\mathrm{NiCo}_{2} \mathrm{~S}_{4}$ nanoflakes supported on nickel foam for electrochemical overall water splitting. Adv. Mater. Interfaces 5, 1701396 (2018). https://doi. org/10.1002/admi.201701396

11. Y. Hou, M. Qiu, G. Nam, M.G. Kim, T. Zhang et al., Integrated hierarchical cobalt sulfide/nickel selenide hybrid nanosheets as an efficient three-dimensional electrode for electrochemical and photoelectrochemical water splitting. Nano Lett. 17, 4202-4209 (2017). https://doi.org/10.1021/acs.nanolett.7b010 30

12. Y. Hou, M. Qiu, T. Zhang, X. Zhuang, C.S. Kim, C. Yuan, $\mathrm{X}$. Feng, Ternary porous cobalt phosphoselenide nanosheets: an efficient electrocatalyst for electrocatalytic and photoelectrochemical water splitting. Adv. Mater. 29, 1701589 (2017). https://doi.org/10.1002/adma.201701589

13. L. Wang, J. Cao, C. Lei, Q. Dai, B. Yang et al., Strongly coupled 3D N-doped $\mathrm{MoO}_{2} / \mathrm{Ni}_{3} \mathrm{~S}_{2}$ hybrid for high current density hydrogen evolution electrocatalysis and biomass upgrading. ACS Appl. Mater. Interfaces 11, 27743-27750 (2019). https ://doi.org/10.1021/acsami.9b06502

14. K.L. Yan, J.F. Qin, ZZh Liu, B. Dong, J.Q. Chi et al., Organicinorganic hybrids-directed ternary NiFeMoS anemone-like nanorods with scaly surface supported on nickel foam for efficient overall water splitting. Chem. Eng. J. 334, 922-931 (2018). https://doi.org/10.1016/j.cej.2017.10.074

15. X. Shang, K.L. Yan, S.S. Lu, B. Dong, W.K. Gao et al., Controlling electrodeposited ultrathin amorphous Fe hydroxides film on V-doped nickel sulfide nanowires as efficient electrocatalyst for water oxidation. J. Power Sources 363, 44-53 (2017). https://doi.org/10.1016/j.jpowsour.2017.07.056

16. X. Li, K.L. Yan, Y. Rao, B. Dong, X. Shang et al., Electrochemically activated $\mathrm{NiSe}-\mathrm{Ni}_{\mathrm{x}} \mathrm{S}_{\mathrm{y}}$ hybrid nanorods as efficient electrocatalysts for oxygen evolution reaction. Electrochim. Acta 220, 536-544 (2016). https://doi.org/10.1016/j.elect acta.2016.10.138 
17. F. Zhang, Y. Pei, Y. Ge, H. Chu, S. Craig et al., Controlled synthesis of eutectic $\mathrm{NiSe} / \mathrm{Ni}_{3} \mathrm{Se}_{2}$ self-supported on $\mathrm{Ni}$ foam: an excellent bifunctional electrocatalyst for overall water splitting. Adv. Mater. Interfaces 5, 1701507-1701509 (2018). https ://doi.org/10.1002/admi.201701507

18. C. Liu, T. Gong, J. Zhang, X. Zheng, J. Mao, H. Liu, Y. $\mathrm{Li}, \mathrm{Q}$. Hao, Engineering $\mathrm{Ni}_{2} \mathrm{P}-\mathrm{NiSe}_{2}$ heterostructure interface for highly efficient alkaline hydrogen evolution. Appl. Catal. B 262, 118245 (2020). https://doi.org/10.1016/j.apcat b.2019.118245

19. H. Hu, J. Zhang, B. Guan, X.W.D. Lou, Unusual formation of CoSe@carbon nanoboxes, which have an inhomogeneous shell, for efficient lithium storage. Angew. Chem. Int. Ed. 55(33), 9514-9518 (2016). https://doi.org/10.1002/ anie. 201603852

20. W. Niu, S. Pakhira, K. Marcus, Z. Li, J.L. Mendoza-Cortes, Y. Yang, Apically dominant mechanism for improving catalytic activities of $\mathrm{N}$-doped carbon nanotube arrays in rechargeable zinc-air battery. Adv. Energy Mater. 8, 1800480 (2018). https://doi.org/10.1002/aenm.201800480

21. C. Lei, H. Chen, J. Cao, J. Yang, M. Qiu et al., $\mathrm{Fe}_{[n .63743]} \mathrm{N} 4$ sites embedded into carbon nanofiber integrated with electrochemically exfoliated graphene for oxygen evolution in acidic medium. Adv. Energy Mater. 8, 1801912 (2018). https ://doi.org/10.1002/aenm.201801912

22. C. Panda, P.W. Menezes, M. Zheng, S. Orthmann, M. Driess, In situ formation of nanostructured core-shell $\mathrm{Cu}_{3} \mathrm{~N}-\mathrm{CuO}$ to promote alkaline water electrolysis. ACS Energy Lett. 4, 747-754 (2019). https://doi.org/10.1021/acsenergyl ett.9b00091

23. C. Lei, Y. Wang, Y. Hou, P. Liu, J. Yang et al., Efficient alkaline hydrogen evolution on atomically dispersed $\mathrm{Ni}-\mathrm{Nx}$ Species anchored porous carbon with embedded Ni nanoparticles by accelerating water dissociation kinetics. Energy Environ. Sci. 12, 149-156 (2019). https://doi.org/10.1039/ C8EE01841C

24. Z. Li, Y. Fang, J. Zhang, X.W.D. Lou, Necklace-like structures composed of $\mathrm{Fe}_{3} \mathrm{~N} @ \mathrm{C}$ yolk-shell particles as an advanced anode for sodium-ion batteries. Adv. Mater. 30(30), 1800525 (2018). https://doi.org/10.1002/ adma.201800525

25. W. Xi, G. Yan, H. Tan, L. Xiao, S. Cheng, S.U. Khan, Y. Wang, Y. Li, Superaerophobic P-doped $\mathrm{Ni}(\mathrm{OH})_{2} / \mathrm{NiMoO}_{4}$ hierarchical nanosheet arrays grown on $\mathrm{Ni}$ foam for electrocatalytic overall water splitting. Dalton Trans. 47, 87878793 (2018). https://doi.org/10.1039/C8DT00765A

26. H. Sun, Z. Ma, Y. Qiu, H. Liu, G. Gao, Ni@NiO nanowires on nickel foam prepared via "acid hungry" strategy: high supercapacitor performance and robust electrocatalysts for water splitting reaction. Small 14, 1800294 (2018). https:// doi.org/10.1002/smll.201800294

27. G. Liu, Z. Sun, X. Zhang, H. Wang, G. Wang, X. Wu, H. Zhang, H. Zhao, Vapor-phase hydrothermal transformation of a nanosheet array structure $\mathrm{Ni}(\mathrm{OH})_{2}$ into ultrathin $\mathrm{Ni}_{3} \mathrm{~S}_{2}$ nanosheets on nickel foam for high-efficiency overall water splitting. J. Mater. Chem. A 6, 19201-19209 (2018). https ://doi.org/10.1039/C8TA07162D

28. K. Akbar, J.H. Jeon, M. Kim, J. Jeong, Y. Yi, S.H. Chun, Bifunctional electrodeposited 3D NiCoSe 2 /nickel foam electrocatalysts for its applications in enhanced oxygen evolution reaction and for hydrazine oxidation. ACS Sustain. Chem. Eng. 6, 7735-7742 (2018). https://doi.org/10.1021/ acssuschemeng.8b00644

29. G. Wang, H. Wang, T. Chen, Y. Tan, Ni1-xMxSe2 $(\mathrm{M}=$ $\mathrm{Fe} \mathrm{Co}, \mathrm{Cu}$ ) nanowires as anodes for ammonia-borane electrooxidation and the derived $\mathrm{Ni1}-\mathrm{xMxSe} 2-\mathrm{y}-\mathrm{OOH}$ ultrathin nanosheets as efficient electrocatalysts for oxygen evolution. J. Mater. Chem. A 7, 16372-16386 (2019). https://doi. org/10.1039/C9TA04681J

30. H. Zhang, X. Li, A. Haehnel, V. Naumann, C. Lin et al., Bifunctional heterostructure assembly of NiFe LDH nanosheets on NiCoP nanowires for highly efficient and stable overall water splitting. Adv. Funct. Mater. 28, 1703257 (2018). https://doi.org/10.1002/adfm.201706847

31. K.N. Dinh, P. Zheng, Z. Dai, Y. Zhang, R. Dangol et al., Ultrathin porous nifev ternary layer hydroxide nanosheets as a highly efficient bifunctional electrocatalyst for overall water splitting. Small 14, 1703257 (2018). https://doi.org/10.1002/ smll.201703257

32. C. Andronescu, S. Seisel, P. Wilde, S. Barwe, J. Masa, Y.T. Chen, E. Ventosa, W. Schuhmann, Influence of temperature and electrolyte concentration on the structure and catalytic oxygen evolution activity of nickel-iron layered double hydroxide. Chem. Eur. J. 24, 13773-13777 (2018). https:// doi.org/10.1002/chem.201803165

33. B. Ren, D. Li, Q. Jin, H. Cui, C. Wang, In-situ tailoring cobalt nickel molybdenum oxide components for overall water-splitting at high current densities. ChemElectroChem 6, 413-420 (2019). https://doi.org/10.1002/celc.201801386

34. J. Zhang, Y. Wang, C. Zhang, H. Gao, L. Lv, L. Han, Z. Zhang, Self-supported porous $\mathrm{NiSe}_{2}$ nanowrinkles as efficient bifunctional electrocatalysts for overall water splitting. ACS Sustain. Chem. Eng. 6, 2231-2239 (2018). https://doi.org/10.1021/ acssuschemeng.7b03657

35. Y. Hou, M. Qiu, T. Zhang, J. Ma, S. Liu, X. Zhuang, C. Yuan, $\mathrm{X}$. Feng, Efficient electrochemical and photoelectrochemical water splitting by a 3D nanostructured carbon supported on flexible exfoliated graphene foil. Adv. Mater. 29, 1604480 (2017). https://doi.org/10.1002/adma.201604480

36. C. Xuan, K. Xia, W. Lei, W. Xia, W. Xiao, L. Chen, H.L. Xin, D. Wang, Composition-dependent electrocatalytic activities of $\mathrm{NiFe}$-based selenides for the oxygen evolution reaction. Electrochim. Acta 291, 64-72 (2018). https://doi.org/10.1016/j. electacta.2018.08.106

37. H. Zhou, Y. Wang, R. He, F. Yu, J. Sun et al., One-step synthesis of self-supported porous $\mathrm{NiSe}_{2} / \mathrm{Ni}$ hybrid foam: an efficient $3 \mathrm{D}$ electrode for hydrogen evolution reaction. Nano Energy 20, 29-36 (2016). https://doi.org/10.1016/j.nanoen.2015.12.008

38. X. Cheng, Z. Pan, C. Lei, Y. Jin, B. Yang et al., A strongly coupled 3D ternary $\mathrm{Fe}_{2} \mathrm{O}_{3} @ \mathrm{Ni}_{2} \mathrm{P} / \mathrm{Ni}\left(\mathrm{PO}_{3}\right)_{2}$ hybrid for enhanced electrocatalytic oxygen evolution at ultra-high current 
densities. J. Mater. Chem. A 7, 965-971 (2019). https://doi. org/10.1039/C8TA11223A

39. J.Q. Chi, X. Shang, F. Liang, B. Dong, X. Li et al., Facile synthesis of pyrite-type binary nickel iron diselenides as efficient electrocatalyst for oxygen evolution reaction. Appl. Surf. Sci. 401, 17-24 (2017). https://doi.org/10.1016/j.apsus c. 2016.12 .243

40. J. Nai, Y. Lu, L. Yu, X. Wang, X.W.D. Lou, Formation of $\mathrm{Ni}-\mathrm{Fe}$ mixed diselenide nanocages as a superior oxygen evolution electrocatalyst. Adv. Mater. 29(41), 1703870 (2017). https ://doi.org/10.1002/adma.201703870

41. J. Zhu, Y. Ni, Phase-controlled synthesis and the phasedependent HER and OER performances of nickel selenide nanosheets prepared by an electrochemical deposition route. CrystEngComm 20, 3344-3352 (2018). https://doi. org/10.1039/C8CE00381E

42. X. Bai, Z. Ren, S. Du, H. Meng, J. Wu, Y. Xue, X. Zhao, H. $\mathrm{Fu}$, In-situ structure reconstitution of $\mathrm{NiCo}_{2} \mathrm{P}_{\mathrm{x}}$ for enhanced electrochemical water oxidation. Sci. Bull. 62, 1510-1518 (2017). https://doi.org/10.1016/j.scib.2017.10.019

43. C. Deng, K.H. Wu, J. Scott, S. Zhu, R. Amal, D.W. Wang, Core/shell NiFe nanoalloy with a discrete n-doped graphitic carbon cover for enhanced water oxidation. ChemElectroChem 5, 732-736 (2018). https://doi.org/10.1002/celc.201701285

44. B. Qiu, A. Han, D. Jiang, T. Wang, P. Du, Cobalt phosphide nanowire arrays on conductive substrate as an efficient bifunctional catalyst for overall water splitting. ACS Sustain. Chem. Eng. 7, 2360-2369 (2019). https://doi.org/10.1021/acssu schemeng.8b05137

45. F. Rong, J. Zhao, Q. Yang, C. Li, Nanostructured hybrid $\mathrm{NiFeOOH/CNT} \mathrm{electrocatalysts} \mathrm{for} \mathrm{oxygen} \mathrm{evolution} \mathrm{reaction}$ with low overpotential. RSC Adv. 6, 74536-74544 (2016). https://doi.org/10.1039/C6RA16450A

46. X. Xu, F. Song, X. Hu, A nickel iron diselenide-derived efficient oxygen-evolution catalyst. Nat. Commun. 7, 12324 (2016). https://doi.org/10.1038/ncomms12324

47. Y. Hou, M.R. Lohe, J. Zhang, S. Liu, X. Zhuang, X. Feng, Vertically oriented cobalt selenide/ $\mathrm{NiFe}$ layered-double-hydroxide nanosheets supported on exfoliated graphene foil: an efficient 3D electrode for overall water splitting. Energy Environ. Sci. 9, 478-483 (2016). https://doi.org/10.1039/c5ee03440j

48. Y. Hou, M. Qiu, M.G. Kim, P. Liu, G. Nam et al., Atomically dispersed nickel-nitrogen-sulfur species anchored on porous carbon nanosheets for efficient water oxidation. Nat. Commun. 10, 1392 (2019). https://doi.org/10.1038/ncomms 12324

49. S. Niu, W.J. Jiang, Z. Wei, T. Tang, J. Ma, J.S. Hu, L.J. Wan, Se-doping activates $\mathrm{FeOOH}$ for cost-effective and efficient electrochemical water oxidation. J. Am. Chem. Soc. 141, 7005-7013 (2019). https://doi.org/10.1021/jacs.9b01214

50. G. Liu, M. Wang, Y. Wu, N. Li, F. Zhao, Q. Zhao, J. Li, 3D porous network heterostructure $\mathrm{NiCe} @ \mathrm{NiFe}$ electrocatalyst for efficient oxygen evolution reaction at large current densities. Appl. Catal. B 260, 118199 (2020). https://doi.org/10.1016/j. apcatb.2019.118199
51. C. Wang, H. Yang, Y. Zhang, Q. Wang, NiFe alloy nanoparticles with hcp crystal structure stimulate superior oxygen evolution reaction electrocatalytic activity. Angew. Chem. Int. Ed. 58, 6099-6103 (2019). https://doi.org/10.1002/anie.20190 2446

52. X. Cheng, C. Lei, J. Yang, B. Yang, Z. Li et al., Efficient electrocatalytic oxygen evolution at extremely high current density over 3D ultrasmall zero-valent iron-coupled nickel sulfide nanosheets. ChemElectroChem 5, 3866-3872 (2018). https://doi.org/10.1002/celc.201801104

53. Y. Fu, H.Y. Yu, C. Jiang, T.H. Zhang, R. Zhan et al., NiCo alloy nanoparticles decorated on $\mathrm{N}$-doped carbon nanofibers as highly active and durable oxygen electrocatalyst. Adv. Funct. Mater. 28, 1705094 (2018). https://doi.org/10.1002/ adfm.201705094

54. M. Bajdich, M. Garcia-Mota, A. Vojvodic, J.K. Norskov, A.T. Bell, Theoretical investigation of the activity of cobalt oxides for the electrochemical oxidation of water. J. Am. Chem. Soc. 135, 13521-13530 (2013). https://doi.org/10.1021/ja405997s

55. Y. Jiao, Y. Zheng, M. Jaroniec, S.Z. Qiao, Design of electrocatalysts for oxygen- and hydrogen-involving energy conversion reactions. Chem. Soc. Rev. 44, 2060-2086 (2015). https ://doi.org/10.1039/c4cs00470a

56. X. Li, G.-Q. Han, Y.-R. Liu, B. Dong, W.-H. Hu, X. Shang, Y.-M. Chai, C.-G. Liu, NiSe@ NiOOH core-shell hyacinthlike nanostructures on nickel foam synthesized by in situ electrochemical oxidation as an efficient electrocatalyst for the oxygen evolution reaction. ACS Appl. Mater. Interfaces 8, 20057-20066 (2016). https://doi.org/10.1021/acsami.6b05597

57. H. Zhou, F. Yu, Y. Huang, J. Sun, Z. Zhu et al., Efficient hydrogen evolution by ternary molybdenum sulfoselenide particles on self-standing porous nickel diselenide foam. Nat. Commun. 7, 12765 (2016). https://doi.org/10.1038/ncomm s12765

58. L. Yu, Q. Zhu, S. Song, B. McElhenny, D. Wang, C. Wu, Z. Qin, J. Bao, Y. Yu, S. Chen, Z. Ren, Non-noble metal-nitride based electrocatalysts for high-performance alkaline seawater electrolysis. Nat. Commun. 10, 5106 (2019). https://doi. org/10.1038/s41467-019-13092-7

59. F. Yu, L. Yu, I.K. Mishra, Y. Yu, Z.F. Ren, H.Q. Zhou, Recent developments in earth-abundant and non-noble electrocatalysts for water electrolysis. Mater. Today Phys. 7, 121-138 (2018). https://doi.org/10.1016/j.mtphys.2018.11.007

60. X. Yu, Z.Y. Yu, X.L. Zhang, Y.R. Zheng, Y. Duan et al., "Superaerophobic" nickel phosphide nanoarray catalyst for efficient hydrogen evolution at ultra-high current densities. J. Am. Chem. Soc. 141, 7537-7543 (2019). https://doi. org/10.1021/jacs.9b02527

61. M. Gong, W. Zhou, M.C. Tsai, J. Zhou, M. Guan et al., Nanoscale nickel oxide/nickel heterostructures for active hydrogen evolution electrocatalysis. Nat. Commun. 5, 4695 (2014). https://doi.org/10.1038/ncomms5695 